\title{
Estudo retrospectivo de afecções cirúrgicas em aves ${ }^{1}$
}

\author{
Patrícia F. Castro ${ }^{2 *}$, Denise T. Fantoni ${ }^{3}$ e Julia M. Matera ${ }^{3}$
}

\begin{abstract}
Castro P.F., Fantoni D.T. \& Matera J.M. 2013. [Retrospective study of surgical disorders in birds.] Estudo retrospectivo de afecções cirúrgicas em aves. Pesquisa Veterinária Brasileira 33(5):662-668. Serviço de Cirurgia de Pequenos Animais-HoVet, Faculdade de Medicina Veterinária e Zootecnia, Universidade de São Paulo, Av. Prof. Dr. Orlando Marques de Paiva 87, Cidade Universitária, São Paulo, SP 05508-270, Brazil. E-mail: pfcastro@usp.br

The study assessed retrospectively avian surgeries at the Service of Small Animal Surgery, Veterinary Hospital of the Faculty of Veterinary Medicine and Animal Science, University of São Paulo, performed during eight years. A total of 90 procedures was done for diagnosis or treatment of surgical disorders. From these, 27 were orthopedic and $63 \mathrm{soft}$ tissue surgeries. Considering the orthopedic surgeries performed according to orders we observed: Psittaciformes 85.19\%, Piciformes 7.41\%, Anseriformes 3.70\%, and Falconiformes 3.70\%; for soft tissues, the Psittaciformes represented 92.06\%, Columbiformes $3.17 \%$, Passeriformes 3.17\%, and Anseriformes 1.60\%. Fractures presented the highest incidence among orthopedic disorders (88.90\%), followed by luxation $(3.70 \%)$, traumatic avulsion of the end (3.70\%) and arthritis/osteomyelitis (3.70\%). Among the surgical disorders of soft tissue, neoplasms accounted in $30.15 \%$, followed by cutaneous neoformation or non-neoplastic annexes (17.46\%), undiagnosed cutaneous neoformations $(7.94 \%)$, dystocia (7.94\%), crop fistula (7.94\%), abdominal hernia (4.76\%), sinusitis (4.76\%), gangrene of the extremities (3.17\%), esophageal perforation (3.17\%), cloaca prolapse (3.17\%), "avascular necrosis of digit" (1.59\%), wound in the region of the keel (1.59\%), perforation of the coelomic cavity (1.59\%), neoformation in the coelomic cavity without a diagnosis (1.59\%), foreign body in the gastrointestinal tract (1.59\%), and otitis (1.59\%). The distribution of surgical disorders according to species affected showed that the "group of parrots", mainly represented by species of Amazonas genus, was prevalent. Knowledge of surgical and bird species most affected add information for those who work in this area and will be an indicator for future surgeons of birds.
\end{abstract}

INDEX TERMS: Surgery, orthopedics, soft tissues, wild animals, psittaciformes.

RESUMO.- Avaliaram-se retrospectivamente as cirurgias realizadas em aves no Serviço de Cirurgia de Pequenos Animais do Hospital Veterinário da Faculdade de Medicina Veterinária e Zootecnia, Universidade de São Paulo, durante período de oito anos. De um total de 90 intervenções cirúrgicas para diagnóstico e/ou tratamento de afecções, 27 foram ortopédicas e 63 de tecidos moles. Quanto ao percentual de cirurgias ortopédicas realizadas segundo

\footnotetext{
${ }^{1}$ Recebido em 6 de março de 2013.

Aceito para publicação em 10 de abril de 2013.

${ }^{2}$ Serviço de Cirurgia de Pequenos Animais- Hospital Veterinário (HoVet), Faculdade de Medicina Veterinária e Zootecnia (FMVZ), Universidade de São Paulo (USP), Av. Prof. Dr. Orlando Marques de Paiva 87, Cidade Universitária, São Paulo, SP 05508-270, Brasil. *Autor para correspondência: pfcastro@usp.br

${ }^{3}$ Departamento de Cirurgia, FMVZ/USP, São Paulo, SP.
}

as diferentes ordens, observou-se: Psittaciformes 85,19\%, Piciformes 7,41\%, Anseriformes 3,70\% e Falconiformes $3,70 \%$. Para as de tecidos moles os Psittaciformes representaram 92,06\%, Columbiformes 3,17\%, Passeriformes $3,17 \%$ e Anseriformes 1,60\%. Entre os tipos de afecções ortopédicas encontradas as fraturas apresentaram a maior ocorrência $(88,90 \%)$, seguidas de luxação $(3,70 \%)$, avulsão traumática de extremidade $(3,70 \%)$ e artrite/osteomielite $(3,70 \%)$. Dentre as afecções cirúrgicas de tecidos moles as neoplasias apresentaram a maior ocorrência $(30,15 \%)$, seguidas das neoformações cutâneas ou de anexos não neoplásicos $(17,46 \%)$, neoformações cutâneas sem diagnóstico $(7,94 \%)$, distocia $(7,94 \%)$, fístula de papo $(7,94 \%)$, hérnia abdominal $(4,76 \%)$, sinusite $(4,76 \%)$, gangrena de extremidade de membros (3,17\%), perfuração de esôfago $(3,17 \%)$, prolapso de cloaca $(3,17 \%)$, "Necrose avascular 
de dígito" (1,59\%), ferida na região da quilha (1,59\%), perfuração de cavidade celomática $(1,59 \%)$, neoformação em cavidade celomática sem diagnóstico $(1,59 \%)$, corpo estranho em trato gastrointestinal $(1,59 \%)$ e otite $(1,59 \%)$. A distribuição das afecções cirúrgicas segundo as espécies acometidas mostrou o "grupo dos papagaios", representado em sua maioria por espécies do gênero Amazona, como prevalente. 0 conhecimento das afecções cirúrgicas e espécies de aves mais acometidas acrescentam informações para aqueles que já atuam nesta área e servem como indicador de estudo para futuros cirurgiões de aves.

TERMOS DE INDEXAÇÃO: Cirurgia, ortopedia, tecidos moles, animais silvestres, psittaciformes.

\section{INTRODUÇÃO}

As aves representam a maioria das espécies da fauna silvestre mantidas como animais de companhia em nosso meio, infelizmente grande parte proveniente do comércio ilegal. Este fato, associado ao aumento da popularidade dos animais exóticos como animais de estimação, resultaram numa demanda crescente pelo atendimento clínico e cirúrgico prestado pelo médico veterinário a esta classe de animais (Fotin 2005).

A medicina de aves, excluindo-se a avicultura, tem uma história muito curta se comparada com outras subdisciplinas da medicina veterinária; a anestesia e a cirurgia de pássaros de companhia eram quase desconhecidas até o final dos anos 1960. 0 desenvolvimento e o aprimoramento da técnica operatória em aves estão intimamente relacionados ao avanço na área da anestesiologia, observado após a introdução do isofluorano como agente anestésico nesta classe em 1985 por Greg Harrison. A partir daí, viabilizou-se a realização de procedimentos cirúrgicos mais longos e complexos (Altman 1998).

Atualmente a literatura internacional em medicina de aves é vasta, porém reflete em sua maioria estudos conduzidos em espécies exóticas à fauna brasileira, enquanto a literatura nacional é restrita a poucas publicações. Diante desta lacuna, nota-se a importância crescente de obtenção de dados nacionais quantitativos e qualitativos nas áreas afins.

Com o objetivo de identificar as afecções cirúrgicas, apresentar sua ocorrência e distribuição de freqüência segundo as ordens e espécies acometidas e comparar os resultados obtidos com os descritos na literatura, este estudo analisou os dados referentes às intervenções cirúrgicas realizadas em aves no Serviço de Cirurgia de Pequenos Animais do Hospital Veterinário da Faculdade de Medicina Veterinária e Zootecnia da Universidade de São Paulo (HoVet-FMVZ/USP), por um período de oito anos.

\section{MATERIAL E MÉTODOS}

Foram analisados individualmente os prontuários de aves submetidas a intervenções cirúrgicas no Serviço de Cirurgia de Pequenos Animais do HoVet-FMVZ/USP, em um período de oito anos. As informações coletadas foram transcritas para um programa de computação desenvolvido para este estudo, associado a um Sistema Gerenciador de Banco de Dados Relacional (SGBDR).

A nomenclatura científica e a ordem taxonômica das espécies de aves ocorrentes em território brasileiro seguiram o Comitê
Brasileiro de Registros Ornitológicos (CBRO 2009) e das espécies de ocorrência internacional o Avibase (Avibase 2009). As espécies ameaçadas de extinção estão de acordo com a Lista das Espécies da Fauna Brasileira Ameaçadas de Extinção do Ministério do Meio Ambiente (Brasil 2003a, b). Para os nomes comuns foram reconhecidos os mais usuais no local em estudo.

Realizou-se a análise dos resultados por meio de consultas ao SGBDR que foram expressos mediante a distribuição numérica $(\mathrm{N})$ e percentual (\%).

\section{RESULTADOS}

Em relação ao número de animais, foram operadas 87 aves pertencentes a seis diferentes ordens: Psittaciformes 89,65\% (78/87), Anseriformes 2,30\% (2/87), Columbiformes 2,30\% (2/87), Piciformes 2,30\% (2/87), Passeriformes 2,30\% (2/87) e Falconiformes 1,15\% (1/87). Do total de aves operadas, 25,29\% (22/87) foram identificadas apenas quanto ao gênero enquanto 74,71\% (65/87) quanto à espécie, dentre as quais três delas, representadas cada uma por um indivíduo, um papagaio-de-cara-roxa (Amazona brasiliensis), um papagaio-de-peito-roxo (Amazona vinacea) e uma arara-azul-grande (Anodorhynchus hyacinthinus), constam da Lista das Espécies da Fauna Brasileira Ameaçadas de Extinção do Ministério do Meio Ambiente (Brasil 2003a, b). 0 "grupo dos papagaios", para o qual foram considerados todos os exemplares pertencentes aos gêneros Amazona e Deroptyus, foi prevalente e representou $67,82 \%(59 / 87)$ das aves operadas.

0 número de intervenções cirúrgicas realizadas totalizou 90 procedimentos, dos quais 30\% (27/90) foram para diagnóstico e/ou tratamento de afecções ortopédicas e $70 \%$ (63/90) para diagnóstico e/ou tratamento de afecções de tecidos moles. Das aves atendidas, uma foi operada duas e outra três vezes.

Quanto ao percentual de cirurgias ortopédicas realizadas segundo as diferentes ordens, observou-se: Psittaciformes 85,19\%, Piciformes 7,41\%, Anseriformes 3,70\% e Falconiformes $3,70 \%$, enquanto para as de tecidos moles os psittaciformes representaram 92,06\%, columbiformes $3,17 \%$, passeriformes $3,17 \%$ e anseriformes $1,60 \%$.

A análise dos dados referentes às 27 cirurgias para diagnóstico e/ou tratamento de afecções ortopédicas permitiu identificar os seguintes tipos de afecções e respectivas ocorrências: fratura $(88,90 \%)$, luxação $(3,70 \%)$, avulsão traumática de extremidade $(3,70 \%)$ e artrite e osteomielite $(3,70 \%)$.

Quanto à distribuição dos diferentes tipos de afecções cirúrgicas ortopédicas segundo os gêneros/espécies acometidos, observou-se apenas um caso de fratura em cisne (Cygnus sp.) da ordem Anseriformes que representou $3,70 \%(1 / 27)$, um caso de fratura e outro de artrite e osteomielite em dois tucanos-toco (Ramphastos toco) da ordem Piciformes que representaram 7,41\% (2/27), e um caso de fratura em um carcará (Caracara plancus) da ordem Falconiformes que representou $3,70 \%(1 / 27)$, os $85,19 \%(23 / 27)$ dos casos restantes ocorreram em espécies pertencentes à ordem Psittaciformes e encontram-se no Quadro 1, na qual se observa o denominado "grupo dos papagaios" (todos os exemplares pertencentes ao gênero Amazona) como preva- 
Quadro 1. Distribuição numérica (N) e percentual (\%) quanto ao tipo das 23 afecções cirúrgicas ortopédicas operadas em psittaciformes segundo as espécies. São Paulo, janeiro de 2000 a junho de 2008

\begin{tabular}{|c|c|c|c|c|c|c|c|c|}
\hline \multirow[t]{2}{*}{$\begin{array}{l}\text { Nome comum } \\
\text { Nome científico }\end{array}$} & \multicolumn{2}{|c|}{ Fratura } & \multicolumn{2}{|c|}{ Luxação } & \multicolumn{2}{|c|}{$\begin{array}{l}\text { Avulsão } \\
\text { traumática }\end{array}$} & \multicolumn{2}{|c|}{ Total } \\
\hline & $\mathrm{N}$ & $\%$ & $\mathrm{~N}$ & $\%$ & $\mathrm{~N}$ & $\%$ & $\mathrm{~N}$ & $\%$ \\
\hline $\begin{array}{l}\text { Papagaio-verdadeiro } \\
\text { Amazona aestiva }^{\text {a }}\end{array}$ & 4 & 17,39 & 0 & 0,00 & 0 & 0,00 & 4 & 17,39 \\
\hline $\begin{array}{l}\text { Papagaio-do-mangue } \\
\text { Amazona amazonica }^{\text {a }}\end{array}$ & 1 & 4,35 & 1 & 4,35 & 0 & 0,00 & 2 & 8,70 \\
\hline $\begin{array}{l}\text { Papagaio-de-peito-roxo } \\
\text { Amazona vinacea }{ }^{\mathrm{a}, \mathrm{b}}\end{array}$ & 1 & 4,35 & 0 & 0,00 & 0 & 0,00 & 1 & 4,35 \\
\hline $\begin{array}{l}\text { Papagaio } \\
\text { Amazona sp. }^{\mathrm{a}}\end{array}$ & 8 & 34,78 & 0 & 0,00 & 0 & 0,00 & 8 & 34,78 \\
\hline $\begin{array}{l}\text { Arara-azul-grande } \\
\text { Anodorhynchus hyacinthinus }\end{array}$ & 1 & 4,35 & 0 & 0,00 & 0 & 0,00 & 1 & 4,35 \\
\hline $\begin{array}{l}\text { Arara-canindé } \\
\text { Ara ararauna }\end{array}$ & 2 & 8,70 & 0 & 0,00 & 0 & 0,00 & 2 & 8,70 \\
\hline $\begin{array}{l}\text { Periquito-verde } \\
\text { Brotogeris sp. }\end{array}$ & 2 & 8,70 & 0 & 0,00 & 0 & 0,00 & 2 & 8,70 \\
\hline $\begin{array}{l}\text { Periquito-australiano } \\
\text { Melopsittacus undulatus }\end{array}$ & 0 & 0,00 & 0 & 0,00 & 1 & 4,35 & 1 & 4,35 \\
\hline $\begin{array}{l}\text { Calopsita } \\
\text { Nymphicus hollandicus }\end{array}$ & 2 & 8,70 & 0 & 0,00 & 0 & 0,00 & 2 & 8,70 \\
\hline TOTAL & 21 & 91,30 & 1 & 4,35 & 1 & 4,35 & 23 & 100,00 \\
\hline
\end{tabular}

a Espécies pertencentes ao gênero Amazona que compõem o "grupo dos papagaios", b espécies da Fauna Brasileira ameaçadas de extinção.

lente representando 55,55\% (15/27) dos casos e $65,22 \%$ $(15 / 23)$ das espécies de psittaciformes.

Os tipos de afecção de tecidos moles e respectivas taxas de ocorrência, identificados após análise dos dados referentes às 63 cirurgias realizadas para diagnóstico e/ ou tratamento foram: neoplasias $(30,15 \%)$, neoformações cutâneas ou de anexos não neoplásicos $(17,46 \%)$, neoformações cutâneas sem diagnóstico $(7,94 \%)$, distocia $(7,94 \%)$, fístula de papo $(7,94 \%)$, hérnia abdominal $(4,76 \%)$, sinusite $(4,76 \%)$, gangrena de extremidade de membros $(3,17 \%)$, perfuração de esôfago $(3,17 \%)$, prolapso de cloaca (3,17\%), "Necrose avascular de dígito" $(1,59 \%)$, ferida na região da quilha $(1,59 \%)$, perfuração de cavidade celomática $(1,59 \%)$, neoformação em cavidade celomática sem diagnóstico (1,59\%), corpo estranho em trato gastrointestinal $(1,59 \%)$ e otite $(1,59 \%)$.

Quanto à distribuição dos diferentes tipos de afecções cirúrgicas de tecidos moles segundo as espécies acometidas observou-se apenas um caso de hérnia abdominal ocorrido em um pato-doméstico (Cairina moschata) da ordem Anseriformes que representou 1,59\% (1/63), um caso de distocia e outro de perfuração de esôfago em dois pombos-domésticos (Columba livia) da ordem Columbiformes que representaram $3,17 \%(2 / 63)$ e dois casos de distocia em dois canários-do-reino (Serinus canaria) da ordem Passeriformes que representaram $3,17 \%(2 / 63)$, sendo que $92,06 \%(58 / 63)$ dos casos restantes ocorreram em espécies pertencentes à ordem Psittaciformes e encontram-se no Quadro 2, na qual se observa o "grupo dos papagaios", para o qual se considerou todos os exemplares pertencentes aos gêneros Amazona e Deroptyus, como prevalente representando $74,60 \%(47 / 63)$ dos casos e $81,03 \%$ (47/58) das espécies de psittaciformes.

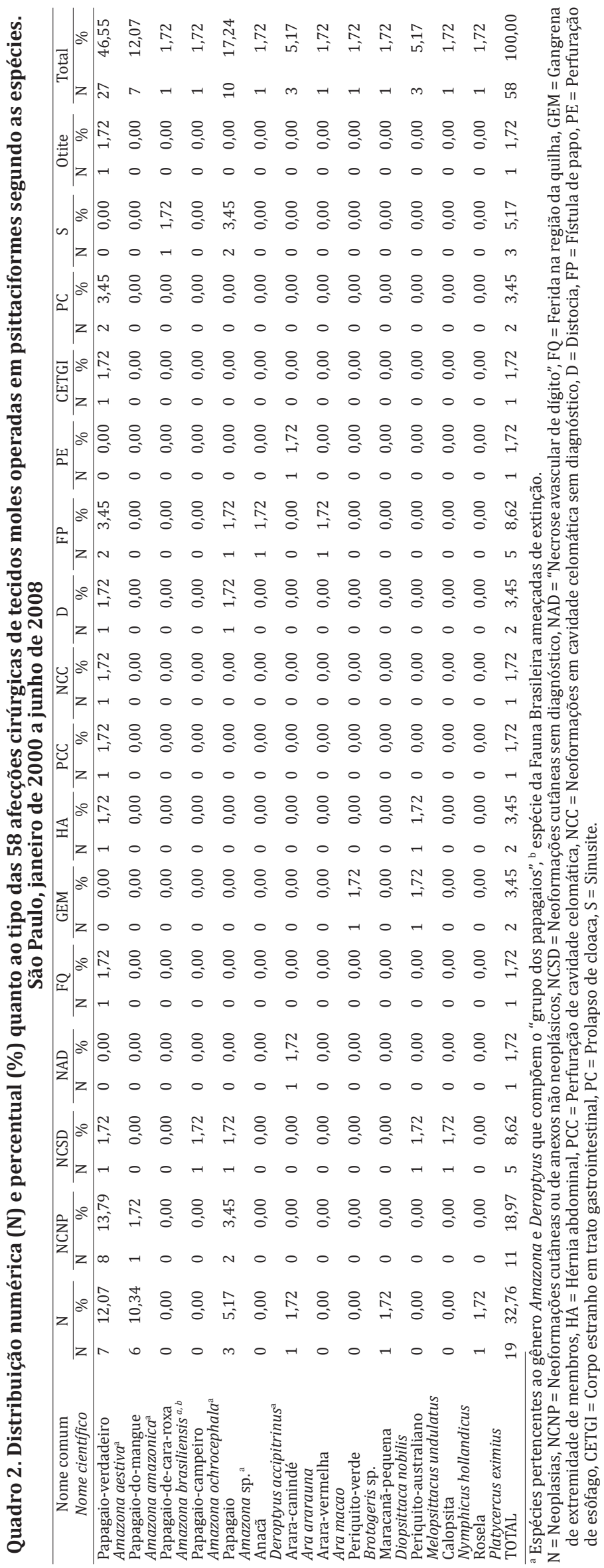

Pesq. Vet. Bras. 33(5):662-668, maio 2013 


\section{DISCUSSÃO}

Bennett \& Harrison (1994) afirmaram que cirurgias em tecidos moles realizadas em aves aumentaram substancialmente na década de 90. De fato, a introdução do isofluorano como agente anestésico para aves em 1985, por Greg Harrison, propiciou aos cirurgiões veterinários a possibilidade de realizar intervenções cirúrgicas até então inexeqüíveis nesta classe de animais (Altman 1998), contudo, limitações para cirurgias abdominais em espécies muito pequenas ou cirurgias torácicas continuam difíceis de serem superadas (Bennett \& Harrison 1994). Neste estudo, o grupo de afecções de tecidos moles respondeu por $70 \%$ das cirurgias realizadas para diagnóstico e/ou tratamento de aves, dentre as quais afecções que necessitaram de cirurgias abdominais (hérnia abdominal, perfuração de cavidade celomática, neoformação em cavidade celomática sem diagnóstico, distocia e corpo estranho em trato gastrointestinal) corresponderam a apenas 17,47\% dos casos e não houve registro de afecções cirúrgicas torácicas, dados que validam o que foi encontrado na literatura.

Outro fator que pode ter contribuído para o número de afecções cirúrgicas de tecidos moles ter superado o de afecções ortopédicas em 2,33 vezes, foi o elevado número de casos de neoplasias (Reavill 2004). Hipoteticamente, se somarmos aos casos de neoplasias àqueles com "potencial neoplásico", classificados como neoformações cutâneas sem diagnóstico e neoformação em cavidade celomática sem diagnóstico, tal soma representaria $27,77 \%$ do total de casos operados, e quase se equipararia aos 30\% de ocorrência de afecções cirúrgicas ortopédicas.

Dentre as ordens de aves de companhia listadas por Burr (1987), as únicas que não ocorreram em nosso estudo foram Galliformes e Strigiformes, em contrapartida, além das ordens Psittaciformes e Passeriformes, citadas por Forbes \& Lawton (1996), as ordens Anseriformes, Columbiformes, Piciformes e Falconiformes também foram observadas. A ocorrência e popularidade distintas das aves nas diversas regiões do mundo justificam parcialmente tais achados e reafirmam a importância de estudos desenvolvidos em nosso meio para a identificação das aves usualmente mantidas como animais de estimação, assim como a identificação dos exemplares da fauna local que possam necessitar de atendimento clínico-cirúrgico.

A prevalência da ordem Psittaciformes dentre o número de aves operadas $(89,65 \%)$, em afecções cirúrgicas ortopédicas $(85,19 \%)$ e de tecidos moles $(92,06 \%)$ - assemelha-se ao resultado descrito por Sinhorini (2008) em estudo com neoplasias (82\%) e supera os $68,09 \%$ observado por Arnaut (2006) em estudo radiográfico, ambos conduzidos com aves na Universidade de São Paulo. Os valores observados neste estudo excedem os achados da casuística de aves atendidas na Bahia por Gondim et al. (2006) cuja prevalência foi 59,31\%, e o valor de 43,48\% dentre as consultas efetuadas por Santos et al. (2008) no Paraná. Os dados obtidos justificam-se, ao considerar que o Brasil possui o maior número de espécies de psitacídeos do planeta, riqueza que foi referência ao país quando em 1500 foi designado como a "Terra dos Papagaios" (Brasilia sive terra papagallorum) (Galetti \& Pizo 2002); confirmam que o grupo dos psitacídeos, inteligentes e hábeis em imitar sons humanos (Forbes \& Lawton 1996), é um dos mais procurados como animal de estimação em nosso meio (Sick 1997); e sugerem serem estas as causas para o predomínio da ordem Psittaciformes neste e nos estudos nacionais acima relacionados.

Arnaut (2006), Sinhorini (2008) e Santos et al. (2008) encontraram a ordem Passeriformes como a segunda em prevalência, representadas respectivamente por $11,70 \%$, $15 \%$ e $26,88 \%$. Isto pode estar relacionado com o relato de Cubas \& Godoy (2007) e Guimarães (2007), que consideram esta ordem a mais popular por contemplar aves de companhia muito reproduzidas no Brasil pelo seu alto valor comercial. A diferença quanto à freqüência de ocorrência desta ordem, que em nosso estudo foi $2,30 \%$, deve-se, provavelmente, ao perfil das aves segundo o tipo de estudo realizado, visto que os passeriformes encontram-se representadas, em geral, por espécimes de pequeno porte, portanto com alto grau de morbidade e mortalidade cirúrgica (Helmer \& Redig 2006) e, por esta razão, compõem um grupo com restrição à realização de cirurgias. De fato, o canário-do-reino (Serinus canaria), que pesa 12-30g (Guimarães 2007), foi a única espécie da ordem Passeriformes operada, e representada neste estudo por apenas dois exemplares, enquanto para Gondim et al. (2006) os canários responderam por $17,24 \%$ do total de consultas a aves.

Enquanto Dilger (1982) considera o periquito-australiano (Melopsittacus undulatus) a ave de gaiola mais popular mantida como "pet", os estudos nacionais de casuística de aves não restritos a afecções específicas, como os de Gondim et al. (2006) e os de Santos et al. (2008) encontraram, respectivamente, os papagaios e o canário (Serinus canaria) como as espécies de maior ocorrência. Em nosso estudo, que abordou exclusivamente afecções cirúrgicas, houve grande disparidade entre a frequência de ocorrência de psittaciformes operados pertencentes ao prevalente "grupo dos papagaios" (67,82\%) em relação às demais espécies. Este grupo superou em 11,8 vezes a segunda espécie mais freqüente, que foi a arara-canindé (Ara ararauna) e em 14,75 vezes a terceira que foi o periquito-australiano (Melopsittacus undulatus). Enquanto criar aves de forma legalizada no Brasil é costume recente em comparação a outros países (Sinhorini 2008), historicamente espécies silvestres acompanharem a sociedade brasileira desde a época colonial, costume introduzido pelas tribos indígenas (Sick 1997), então, a identificação neste estudo de três exemplares que constam da Lista das Espécies da Fauna Brasileira Ameaçadas de Extinção do Ministério do Meio Ambiente (Brasil 2003a, 2003b), incita a suspeita de que a maioria das aves pertencentes ao "grupo dos papagaios" tenha sido capturada da natureza e comercializada ilegalmente, como observado por Fotin (2005) em São Paulo e constatado por Gondim et al. (2006) na Bahia, onde 100\% das aves nativas atendidas foram adquiridas através do comércio ilegal.

O predomínio das fraturas sobre as demais afecções ortopédicas, encontrado na literatura (McCartney 1994, Arnaut 2006, Santos et al. 2008) e confirmado por este estudo, justifica-se, visto que as corticais ósseas finas e frágeis das aves tendem a fragmentar-se quando submetidas à for- 
ça imposta sobre elas (Blass 1987) e há pouco tecido mole cobrindo os ossos para protegê-los (Helmer \& Redig 2006). Em contrapartida, luxações apresentam baixa ocorrência (McCartney 1994, Santos et al. 2008) sendo raras as luxações de joelho (Bennett 1997), representadas por apenas um caso ocorrido em um papagaio-do-mangue (Amazona amazonica). Nas aves as luxações são menos comuns que as fraturas devido à característica pneumática dos ossos e de seus ligamentos bem desenvolvidos. Forças aplicadas na área do joelho quase sempre produzirão fratura ao invés de luxação (Blass 1987).

A ocorrência de apenas um caso de avulsão de extremidade de membro pélvico em um periquito-australiano (Melopsittacus undulatus) contrapõe-se a Quesenberry et al. (1997), segundo os quais o traumatismo aos dígitos está entre as injúrias mais comumente vistas na clínica de aves. Para o único caso de artrite e osteomielite, que envolveu a articulação intertársica de um tucano-toco (Ramphastos toco), o diagnóstico ocorreu através de colheita de material (histopatológico e cultura/antibiograma), que indicou infecção bacteriana, conforme indicado por Arnaut (2006).

As injúrias traumáticas estão entre as afecções mais encontradas pelos veterinários cirurgiões que trabalham com psitacídeos (Simpson 1996) e a redução de fraturas é uma das intervenções cirúrgicas mais freqüentes para este grupo (Godoy 2007). De fato, os achados deste estudo mostraram ocorrência de $100 \%$ de afecções cirúrgicas ortopédicas traumáticas entre os psitacídeos atendidos; dentre as afecções de tecidos moles observou-se um caso de perfuração de cavidade celomática e outro de ferida na região da quilha, ambos causados por mordedura de cão, em dois papagaios-verdadeiro (Amazona aestiva). Observou-se também que 91,30\% das fraturas acometeram a ordem Psittaciformes.

Com o crescimento do conhecimento e melhora da qualidade da clínica de aves, as doenças neoplásicas vêm se tornando mais que um diagnóstico posmortem (Reavill 2004), o que pode ser comprovado pelo predomínio das neoplasias $(30,15 \%)$ sobre as demais afecções cirúrgicas de tecidos moles observadas neste estudo, e também por taxas de ocorrência superiores às de tumores observadas por estudos na área da patologia de 3,9\% (Reece 1992) e $5,8 \%$ (Garner 2006) e no levantamento geral de doenças $(4,95 \%)$ notada por Santos et al. (2008).

A maior freqüência de casos de neoplasias ocorre em Psittaciformes, segundo grande parte da literatura consultada (Reece 1992, Sinhorini 2008), e corrobora com os achados deste estudo, para o qual a ocorrência de neoplasias deu-se exclusivamente em exemplares psittaciformes, contrapondo-se a Garner (2006), que encontrou na ordem Anseriformes a maior taxa de prevalência tumoral. A ocorrência e popularidade distintas das aves nas diversas regiões do mundo podem justificar tais achados. Na literatura nacional encontram-se diversos relatos de caso de neoplasias em psitacídeos (Araújo et al. 2007, Freitas et al. 2008, Sarmento et al. 2008).

Para Garner (2006) a calopsita (Nymphicus hollandicus) seguida do papagaio (Amazona sp.) foram as espécies psittaciformes com maior prevalência tumoral; já Sinhorini (2008) encontrou o periquito-australiano seguido do gêne- ro Amazona, enquanto nosso estudo mostrou que o "grupo dos papagaios" respondeu pela maioria dos casos de neoplasias operados. Como discutido anteriormente, aves de pequeno porte apresentam maior grau de morbidade e mortalidade cirúrgica (Helmer \& Redig 2006), o que faz com que os proprietários destes animais em sua maioria desistam do procedimento. Isto justifica ter sido uma rosela (Platycercus eximius) o menor dos psitacídeos operados para exérese tumoral identificado por este estudo.

As neoformações cutâneas ou de anexos não neoplásicos, que apresentaram a segunda maior ocorrência entre as afecções de tecidos moles operadas, acometeram exclusivamente os psittaciformes, corroborando com Godoy (2007), para o qual a remoção de cáseos constitui-se uma das intervenções cirúrgicas mais freqüentes em psitacídeos.

As neoformações cutâneas sem diagnóstico foram assim denominadas, pois não foi possível estabelecer o diagnóstico final quanto à sua etiologia, por motivos em sua maioria relacionados à decisão dos proprietários pela não realização de exames (histopatológico, cultura/antibiograma e/ ou necropsia). Este grupo de afecções, se portadores de um diagnóstico etiológico definitivo, pertenceriam ao grupo das neoplasias ou ao das neoformações cutâneas e/ou de anexos não neoplásicos, portanto teríamos mudanças nos valores numéricos absolutos e percentuais e não ordem de classificação de ocorrência das afecções.

A ocorrência de distocia entre as afecções de tecidos moles $(7,94 \%)$ superou aquela encontrada por Santos et al. (2008) entre as doenças gerais de aves $(0,85 \%)$, resultado que se justifica pois este estudo esteve restrito às afecções cirúrgicas. Discordando em parte de Bennett \& Harrison (1994), para os quais esta afecção acomete particularmente patos e psitacídeos, as espécies aqui acometidas pertenciam às ordens Psittaciformes, Columbiformes e Passeriformes.

Dos vários segmentos do trato digestório das aves, o inglúvio foi o que mais necessitou de intervenção cirúrgica (Gandal 1982), devido à ocorrência de fístula resultante da queimadura térmica causada pela administração de alimento superaquecido (Bennett \& Harrison 1994), afecção que acometeu exclusivamente os psittaciformes, corroborando com Godoy (2007), para o qual o reparo de queimaduras ingluviais constitui-se uma das intervenções cirúrgicas mais frequentes.

Forbes (2002) refere que a hérnia abdominal é encontrada com maior freqüência em fêmeas obesas de psitacídeos, principalmente cacatuas e periquitos, assemelhando-se em parte aos resultados obtidos, que mostraram a ocorrência de hérnia abdominal em dois psitacídeos, sem identificação do sexo, um deles um periquito-australiano e o outro um papagaio-verdadeiro, além de acometer uma fêmea de pato-doméstico que havia efetuado postura recentemente, e que por este motivo provavelmente teve sua musculatura abdominal submetida à pressão (Gandal 1982).

Altman (1997) afirma que a infecção dos seios nasais é um dos problemas respiratórios mais comuns em aves, principalmente psitacídeos, e Godoy (2007) cita a remoção de cáseos ou coleções líquidas decorrentes das sinusites como uma das intervenções cirúrgicas mais freqüentes 
para estas aves. De fato, neste estudo, a sinusite que acometeu exclusivamente os psittaciformes, aparece como a quarta afecção cirúrgica de tecidos moles de maior ocorrência para este grupo.

Lacerações causadas por mordedura em um pombo-doméstico (Columba livia) e por um corpo estranho em uma arara-canindé (Ara ararauna) representaram as causas de perfuração de esôfago observadas neste estudo e sustentadas por Forbes (2002).

Enquanto na literatura internacional as cacatuas são consideradas os psitacídeos mais acometidos por prolapso de cloaca (Bennett \& Harrison 1994, Altman 1997, Forbes 2002, Bowles et al. 2006), este estudo mostrou o papagaio-verdadeiro (Amazona aestiva) como a única espécie de psitacídeo acometido por esta afecção. Se considerarmos que a sua etiologia ainda não é totalmente conhecida, mas atribuída a um déficit neuromuscular da parede da cloaca com redução do tônus do esfíncter (Bennett \& Harrison 1994, Altman 1997, Bowles et al. 2006), que pode estar relacionado à masturbação crônica ou colacites (Bowles et al. 2006), é provável que as espécies tidas como "mais acometidas" não representem as mais predispostas mas sim aquelas que ocorrem em maior freqüência no local do estudo.

A baixa freqüência de casos de gangrena de extremidade de membros decorrentes de extensa lesão aos tecidos moles, que acometeu um periquito-verde (Brotogeris sp.) e um periquito-australiano (Melopsittacus undulatus), não correspondeu à assertiva de Quesenberry, Orosz \& Dorrestein (1997), de que as feridas traumáticas de dígitos estão entre as injúrias mais comumente vistas na prática da clínica aviária, assim como a "Necrose avascular de dígito", considerada freqüente em psitacídeos pelos mesmos autores, que foi representada neste estudo por um único caso observado em uma arara-canindé (Ara ararauna),e que correspondeu a apenas $1,72 \%$ das afecções cirúrgicas de tecidos moles que acometeram os psittaciformes, e cujo exame histopatológico revelou uma dermatite hiperplásica crônica de dígito, sem evidência de constricção mecânica, hipótese etiológica defendida por Harcourt-Brown (1996).

Formações neoplásicas ou de outra origem em cavidade celomática podem apresentar-se com sinais de dispnéia em psitacídeos (Forbes 1996), como observado em um papagaio-verdadeiro (Amazona aestiva) com neoformação sem diagnóstico em cavidade celomática.

Corpos estranhos que passam pelo inglúvio podem se alojar em qualquer parte do sistema digestório (Gandal 1982). De fato, o único caso de corpo estranho em trato gastrointestinal, localizado em proventrículo e ventrículo de um papagaio-verdadeiro (Amazona aestiva), tratava-se de uma sonda empregada para alimentar a ave.

Na literatura, a otite é dentre as afecções de ouvido a mais citada apesar da baixa ocorrência e que pode necessitar de curetagem cirúrgica para auxílio no tratamento médico (Altman 1997), informações que correspondem ao que foi demonstrado por este estudo, tendo ocorrido um único caso de otite em um papagaio-verdadeiro (Amazona aestiva).

Por tratar-se do primeiro estudo retrospectivo relacio- nado à casuística de cirurgias em aves desenvolvido no Brasil, e considerando sua importância para o mapeamento das diferentes afecções que possam necessitar de tratamento cirúrgico, estudos futuros sobre o tema devem ser empreendidos no país, que possui a terceira maior diversidade de aves no mundo. 0 conhecimento das afecções cirúrgicas e respectivas espécies de aves mais acometidas acrescentam informações para aqueles que atuam nesta área e servem como indicador de estudo para futuros cirurgiões de aves.

Agradecimentos.- À médica veterinária Marta B. Guimarães do Ambulatório de Aves do HoVet-FMVZ/USP pelo encaminhamento e acompanhamento dos casos.

\section{REFERÊNCIAS}

Altman R.B. 1997. Soft tissue surgical procedures, p.704-732. In: Altman R.B., Clubb S.L., Dorrestein G.M. \& Quesenberry K. (Eds), Avian Medicine and Surgery. W.B. Saunders, Philadelphia. 1070p.

Altman R.B. 1998. Twenty years of progress in avian anesthesia and surgery. J. Am. Vet. Med. Assoc. 212:1233-1235.

Araújo A.C.P., Carvalho A.D., Nascimento P.B., Voll J. \& Driemeier D. 2007. Rabdomiossarcoma alveolar em papagaio (Amazona aestiva). Acta Scient. Vet. 35:115-117.

Arnaut L.S. 2006. Estudo radiográfico das afecções do sistema esquelético em aves. Dissertação de Mestrado em Clínica Cirúrgica Veterinária, Faculdade de Medicina Veterinária e Zootecnia, Universidade de São Paulo, São Paulo, SP. 121p.

Avibase 2009. The World Bird Database. Disponível em <http://www. ao.com.br> Acesso em 20 out. 2009.

Bennett R.A. 1997. Orthopedic surgery, p.733-766. In: Altman R.B., Clubb S.L., Dorrestein G.M. \& Quesenberry K. (Eds), Avian Medicine and Surgery. W.B. Saunders, Philadelphia. 1070p.

Bennett R.A. \& Harrison G.J. 1994. Soft tissue surgery, p.1096-1136. In: Ritchie B.W., Harrison G.J. \& Harrison L.R. (Eds.), Avian Medicine: principles and application. Wingers, Florida. 1384p.

Blass C.E. 1987. Orthopedics, p.155-165. In: Burr E.W. (Ed), Companion Bird Medicine. Iowa State University Press, Ames. 247p.

Bowles H.L., Odberg E., Harrison G.J. \& Kottwitz J.J. 2006. Surgical resolution of soft tissue disorders, p.775-829. In: Harrison G.J. \& Lightfoot T.L. (Eds), Clinical Avian Medicine. Vol.2. Spix, Florida. 1004p.

Brasil 2003a. Instrução Normativa no 3, de 26 de maio de 2003. Ministério do Meio Ambiente, Brasília, DF. Disponível em <http://www.icmbio.gov. br/sisbio/legislacao.php?id_arq=29> Acesso em 20 out. 2009.

Brasil 2003b. Anexo à Instrução Normativa n 3, de 27 de maio de 2003. Ministério do Meio Ambiente, Brasília, DF. Disponível em <http://www.ibama.gov.br/fauna/downloads/lista\%20spp.pdf> Acesso em 20 out. 2009.

Burr E.W. 1987. Companion Bird Medicine. Iowa State University Press, Ames. 247p.

CBRO 2009. Listas das Aves do Brasil. 8ª ed. Versão 9/8/2009. Comitê Brasileiro de Registros Ornitológicos. Disponível em <http://www.cbro. org.br> Acesso em 20 out. 2009.

Cubas Z.S. \& Godoy S.N. 2007. Medicina e patologia de aves de companhia, p.213-264. In: Aguilar R., Hernández-Divers S.M. \& Hernández-Divers S.J. (Eds), Atlas de Medicina, Terapêutica e Patologia de Animais Exóticos. Interbook, São Caetano do Sul. 375p.

Dilger W.C. 1982. Common types of cage birds, p.3-10. In: Petrak M.L. (Ed.), Diseases of Cage and Aviary Birds. $2^{\text {nd }}$ ed. Lea and Febiger, Philadelphia. 680p.

Forbes N.A. 2002. Avian gastrointestinal surgery. Seminars in Avian and Exotic Pet Medicine 11:196-207.

Forbes N.A. 1996. Respiratory problems, p.147-157. In: Beynon P.H., Forbes N.A. \& Lawton M.P.C. (Eds), Manual of Psittacine Birds. BSAVA, Cheltenham. 239p. 
Forbes N.A. \& Lawton M.P.C. 1996. Introduction, p.7-10. In: Beynon P.H., Forbes N.A. \& Lawton M.P.C. (Eds), Manual of Psittacine Birds. BSAVA, Cheltenham. 239p.

Fotin C.M.P. 2005. Levantamento prospectivo dos animais silvestres, exóticos e domésticos não convencionais, em cativeiro domiciliar, atendidos em clínicas particulares no município de São Paulo: aspectos do manejo e principais afecções. Dissertação de Mestrado em Patologia Experimental e Comparada, Faculdade de Medicina Veterinária e Zootecnia, Universidade de São Paulo, São Paulo, SP. 206p.

Freitas A.A.R., Levy M.G.B., Nogueira D.M., Liparisi F. \& Tortelly R. 2008. Carcinoma de células basais em periquito australiano (Melopsittacus undulatus): relato de caso. Revta Bras. Ciênc. Vet. 15:25-27.

Galetti M. \& Pizo M.A. 2002. Ecologia e Conservação de Psitacídeos no Brasil. Melopsittacus Publicações Científicas, Belo Horizonte. 235p.

Gandal C.P. 1982. Anesthetic and surgical techniques, p.304-328. In: Petrak M.L. (Ed), Diseases of Cage and Aviary Birds. $2^{\text {nd }}$ ed. Lea and Febiger, Philadelphia. 680p.

Garner M.M. 2006. A retrospective study of case submissions to a specialty diagnostic service, p.566-571. In: Harrison G.J. \& Lightfoot T.L. (Eds), Clinical Avian Medicine. Vol.2. Spix, Florida. 1004p.

Godoy S.N. 2007. Psittaciformes (arara, papagaio, periquito), p.222-251. In: Cubas Z.S., Silva J.C.R. \& Catão-Dias J.L. (Eds), Tratado de Animais Selvagens: medicina veterinária. Roca, São Paulo. 1354p.

Gondim L.S.Q., Gomes D.M. \& Maia P.C.C. 2006. Casuística de aves selvagens atendidas de 2002 a 2004 na Escola de Medicina Veterinária da Universidade Federal da Bahia. Anais 26을 Congresso Brasileiro de Zoologia, Londrina, PR, p.86-87. (Resumo)

Guimarães M.B. 2007. Passeriformes (pássaro, canário, saíra, gralha), p.324-337. In: Cubas Z.S., Silva J.C.R. \& Catão-Dias J.L. (Eds), Tratado de Animais Selvagens: medicina veterinária. Roca, São Paulo. 1354p.
Harcourt-Brown N.H. 1996. Pelvic limb problems, p.123-133. In: Beynon P.H., Forbes N.A. \& Lawton M.P.C. (Eds), Manual of Psittacine Birds. BSAVA, Cheltenham. 239p.

Helmer P. \& Redig P.T. 2006. Surgical resolution of orthopedic disorders, p.761-773. In: Harrison G.J. \& Lightfoot T.L. (Eds), Clinical Avian Medicine. Vol.2. Spix, Florida. 1004p.

McCartney W.T. 1994. Orthopaedic injuries in pigeons. Vet. Rec. 134:305307.

Quesenberry K., Orosz S. \& Dorrestein G.M. 1997. Musculoskeletal system, p.517-539. In: Altman R.B., Clubb S.L., Dorrestein G.M. \& Quesenberry K. (Eds), Avian Medicine and Surgery. W.B. Saunders, Philadelphia. 1070p.

Reavill D.R. 2004. Tumors of pet birds. Vet. Clin. Exotic Anim. Pract. 7:537560.

Reece R.L. 1992. Observations on naturally occurring neoplasms in birds in the state of Victoria, Australia. Avian Pathol. 21:3-32.

Santos G.C., Matuella G.A., Coraiola A.M., Silva L.C., Lange R.R. \& Satin E. 2008. Doenças de aves selvagens diagnosticadas na Universidade Federal do Paraná (2003-2007). Pesq. Vet. Bras. 28:565-570.

Sarmento R.M., Sanches A.W.D. \& Pachaly J.R. 2008. Tumor maligno de bainha nervosa em papagaio-verdadeiro (Amazona aestiva): relato de caso. Clín. Vet. 74:46-50.

Sick H. 1997. Ornitologia Brasileira. Nova Fronteira, Rio de Janeiro. 912p.

Simpson G.N. 1996. Trauma, p.186-189. In: Beynon P.H., Forbes N.A. \& Lawton M.P.C. (Eds), Manual of Psittacine Birds. BSAVA, Cheltenham. 239 p.

Sinhorini J.A. 2008. Neoplasias em aves domésticas e silvestres mantidas em domicílio: avaliação anatomopatológica e imunoistoquímica. Dissertação de Mestrado em Patologia Experimental e Comparada, Faculdade de Medicina Veterinária e Zootecnia, Universidade de São Paulo, São Paulo, SP. 131p. 